\title{
ANALISIS DAMPAK LALU LINTAS REVITALISASI PASAR SUMBERGEMPOL KABUPATEN TULUNGAGUNG
}

\author{
Aris Styawan *1, Yosef Cahyo S.P ${ }^{2}$, Ahmad Ridwan³. \\ ${ }_{1,2,3}$ Fakultas Teknik, Universitas Kadiri. \\ e-mail:*1 aristyawan139@gmail.com,2yosef.cs@unik-kediri.ac.id., \\ 3 ahmad ridwan@unik-kediri.ac.id.
}

\begin{abstract}
Traffic Impact Analysis (Andalalin) is an analysis of the influence of land use development on the system movement of surrounding traffic flows. It studies the method described in the 1997 MKJI concludes: 1. The revitalization of Sumbergempol People's Market is expected to attract trips of 88.9 SMP / hour and generate trips of 60.6 SMP / hour. 2. The results of the study area. The condition of the road section prior to revitalization has a V / C ratio of 0.53 with a Service Level in C. b. Predictions in 2019 have a V / C ratio of 0.57. c. Prediction in 2024 has a V / C ratio of 0.61, the performance still in category $C .3$ The impact of the service level of the road section based on PM 96th. 2015 is: - The flow is stable, but vehicle movement is controlled by higher traffic volumes with speeds of at least $60 \mathrm{~km} / \mathrm{hour}$ - Medium traffic density due to internal obstacles to increased traffic. - Drivers have limitations for speed, change lanes, and overtake. 4. The market developer must provide a motorcycle parking area with a minimum area of 144.3 $\mathrm{m}^{2}$ and $1203.13 \mathrm{~m}^{2}$ for cars.
\end{abstract}

Keywords: Traffic Impact, Pull, Awakening, Level Of Service (LOS), Parking

\begin{abstract}
Abstrak
Analisis Dampak Lalu Lintas (Andalalin) adalah analisis pengaruh perkembangan tata guna lahan terhadap sistem pergerakan arus lalu lintas disekitar, Dalam penelitian Andalalin ini metode yang dijelaskan dalam MKJI 1997 yangkesimpulannya: 1. Revitalisasi Pasar Rakyat Sumbergempol diperkirakan akan menarik perjalanan sebesar $88,9 \mathrm{smp} / \mathrm{jam}$ dan membangkitkan perjalanan sebesar 60,6 smp/jam. 2. Hasil penelitian adalah: a. Kondisi ruas jalan sebelum dilakukan Revitalisasi mempunyai V/C Ratio 0,53 yang Level Tingkat Pelayanan nya dalam kategori C. b. Prediksi pada tahun 2019 mempunyai V/C Ratio 0,57. c. Prediksi pada tahun 2024 mempunyai V/C Ratio 0,61, kinerja ruas jalan raya mengalami penurunan tapi Level Tingkat pelayanan masih dalam kategori C. 3 Dampak dari tingkat pelayanan ruas jalan berdasarkan PM No. 96 th. 2015 adalah: - Arus stabil, tetapi pergerakan kendaraan di kendalikan oleh volume lalu lintas yang lebih tinggi dengan kecepatan sekurang-kurangnya $60 \mathrm{~km} / \mathrm{jam}$. - Kepadatan lalu lintas sedang karena hambatan internal lalu lintas meningkat. - Pengemudi memiliki keterbatasan untuk kecepatan, pindah jalur dan mendahului. 4. Pihak pengembang pasar harus menyediakan tempat parkir motor minimal luasan harus 144,3 $\mathrm{m}^{2}$ dan untuk mobil minimal luasan harus $1203,13 \mathrm{~m}^{2}$.
\end{abstract}

Kata Kunci : $\quad$ Dampak Lalu Lintas, Tarikan, Bangkitan, Tingkat Pelayanan (LOS), Parkir. 


\section{PENDAHULUAN}

Analisis Dampak Lalu Lintas (Andalalin) adalah analisis pengaruh perkembangan tata guna lahan terhadap pergerakan arus lalu lintas baru, lalu lintas beralih, dan oleh kendaraan yang keluar masuk suatu lahan [1][2][3].

Dengan Adanya pengembangan kawasan fasilitas umum atau sosial akan menimbulkan dampak terhadap lalu lintas sekitar. Oleh sebab itu perlu dilakukannya Andalalin. Revitalisasi Pasar Sumbergempol Kabupaten Tulungagung di perkirakan akan menarik dan membangkitakn arus lalu lintas di wilayah sekitar, oleh karena itu perlu dilakukannya Andalalin, yang menurut referensi [4][5][6]. Analisis Dampak Lalu lintas dipergunakan untuk memprediksi apakah infrastruktur transportasi dalam daerah pengaruh pebangunan tersebut dapat melayani lalu lintas yang ada (ekisting) di tambah dengan lalu lintas yang dibangkitkan atau ditarik oleh perkembangan wilayah tersebut.

\section{METODE PENELITIAN}

\subsection{Lokasi Penelitian.}

Penelitian ini dilaksanakan di kabupaten Tulungagung Propinsi Jawatimur tepatnya di Pasar Sumbergempol yang terletak di jalan raya Tulungagung - Blitar desa Sumberdadi.

\subsection{Pengertian Andalalin}

Andalalin merupakan serangkaian kegiatan kajian mengenai dampak lalu lintas dari pembangunan pusat kegiatan, pemukiman, dan infrastruktur yang hasilnya di tuangkan dalam bentuk dokumen hasil analisis dampak lalu lintas.[7]

\subsection{Fenomena Dampak Lalu Lintas.}

Menurut referensi [8][9] Setiap ruang kegiatan akan "membangkitkan" pergerakan dan "menarik" pergerakan yang intensitasnya tergantung pada jenis tata guna lahannya.

Besar kecilnya dampak kegiatan terhadap lalu lintas di pengaruhi oleh : a. Bangkitan perjalanan, b. Menarik tidaknya suatu pusat kegiatan, c. Tingkat kelancaran lalu lintas pada jalan, d. Prasarana jalan di sekitar pusat kegiatan, e. Jenis tarikan perjalanan, f. kompetisi beberapa pusat kegiatan.

\subsection{Sasaran Analisis Dampak Lalu Lintas.}

Sasaran Andalalin di tekankan pada :

a. Penilaian dan formulasi dampak lalu lintas yang ditimbulkan oleh daerah pembangunan terhadap jaringan jalan di sekitarnya;

b. Upaya sinkronisasi terhadap kebijakan pemerintah dalam kaitannya dalam penyediaan prasarana jalan; 
c. Penyediaan solusi-solusi yang menimbulkan kemacetan lalu lintas oleh dampak pembangunan, serta penyusunan usulan indikatif terhadap fasilitas tambahan yang diperlukan guna mengurangi dampak yang diakibatkan oleh lalu lintas yang di bangkitkan oleh pembangunan, serta mempertahankan tingkat pelayanan prasarana jaringan jalan yang ada

d. Penyusunan rekomendasi pengaturan sistem jaringan jalan.”

\subsection{Tinjauan Pelaksanaan Andalalin.}

Pelaksanaan analisis dampak lalu lintas di beberapa wilayah bervariasi berdasarkan kriteria atau pendekatan tertentu. Ketentuan mengenai lalu lintas jalan yang berlaku sekarang sebagaimana dalam Undang-Undang Lalu Lintas Jalan Nomor 22 tahun 2009 tentang lalu lintas dan angkutan jalan.Berdasarkan [7][10], ukuran minimal peruntukan lahan Pusat Pembelanjaan / Pasar yang wajib melalakukan Andalalin adalah yang memiliki Ukuran material $2000 \mathrm{~m} 2 \mathrm{Luas}$ Lantai.

\subsection{Bangkitan Perjalanan / Pergerakan (Trip Generation).}

Menurut [11], bangkitan / tarikan pergerakan adalah tahapan pemodelan yang memperkirakan jumlah pergerakan yang berasal dari suatu zona atau lahan dan jumlah pergerakan yang tertarik ke suatu tata guna lahan atau zona.Pergerakan lalu lintas merupakan fungsi tata guna lahan yang menghasilkan pergerakan lalu lintas. Ada dua pembangkit pergerakan yaitu : a.Lalu lintas yang meninggalkan lokasi; b. Lalu lintas yang menuju atau tiba di lokasi tersebut.

\subsection{Prakiraan Lalu Lintas.}

Secara umum terdapat 4 tahapan kegiatan yang harus dilalui dalam melakukan prakiraan lalu lintas ; Tahap penetapan Sistem Zona, Tahap Bangkitan Perjalanan,Tahap Distribusi Perjalanan,Tahap Pembebanan Lalu lintas

\subsection{Perencanaan Transportasi dan Kinerja Jalan.}

Menurut [12], hubungan antara lalu lintas dengan tata guna lahan dapat dikembangkan melalui suatu proses perencanaan transportasi yang saling terkait, terdiri atas : Bangkitan / tarikan perjalanan, Penyebaran perjalanan, Pembebanan lalu lintas, Pemilihan moda.

\subsection{Geometrik Jalan}

Geometrik Jalan merupakan informasi yang sangat penting dalam rangka melakukan analisis pada ruas jalan.Oleh karena itu dilakukan inventarisasi kondisi jalan sebelum melakukan perhitungan dengan menggunakan metode yang telah dijelaskan dalam MKJI (1997).

\subsection{Karakteristik Jalan}

Segmen jalan perkotaan meliputi empat tipe jalan yaitu : Jalan Sedang tipe 2/2TT,Jalan 
Raya tupe 4/2T, Jalan Raya tipe 6/2T, Jalan Satu Arah tipe 1/1,2/1, dan 3/1. Setiap tipe jalan memiliki ketentuan-ketentuan untuk menganalisisnya.

\subsection{Karakteristik arus lalu lintas}

Arus lalu lintas merupakan volume lalu lintas pada suatu jalan raya yang diukur berdasarkan jumlah kendaraan yang melewati titik tertentu selama selang waktu tertentu [13].

\subsection{Volume Lalu Lintas.}

\subsubsection{Karakteristik volume lalu lintas}

Menurut [14], "Volume lalu lintas adalah banyaknya kendaraan yang melewati suatu titik pengamatan dalam satuan waktu (hari, jam, menit). Satuan volume lalu lintas umumnya dipergunakan sehubungan dengan penentuan jumlah dan lebar lajur adalah : Lalu Lintas Harian Rata-rata, Volume jam perencanaan, dan Kapasitas.”

\subsubsection{Satuan Mobil Penumpang}

Satuan mobil penumpang adalah metode yang diciptakan para ahli rekayasa lalu lintas dalam memberikan faktor-faktor yang memungkinkan adanya pokok tolok ukur besarnya ruang permukaan jalan yang terpakai oleh setiap pemakai jalan yang beraneka jenis. Setiap kendaraan memiliki karakteristik yang berbeda, oleh karena itu untuk menyamakan digunakan suatu satuan yang bisa dipakai dalam perencanaan lalu lintas yang disebut Satuan Mobil Penumpang (SMP) yang sebagaimana telah dijelaskan dalam[15].

\subsubsection{Kapasitas Ruas Jalan}

Menurut, [16] Kapasitas adalah arus lalu lintas maksimum (smp/jam) yang dapat dipertahankan sepanjang segmen jalan tertentu dalam kondisi tertentu (sebagai contoh: geometrik, lingkungan, lalu lintas dan lain- lain). Perhitungan kapasitas jalan perkotaan menurut [16] adalah sebagai berikut :

$$
C=C_{0} \times F C_{w} \times F C_{s f} \times F C_{c s}\left(\frac{s m p}{j a m}\right)
$$

C : Kapasitas (smp/jam)

$\mathrm{C}_{\mathrm{o}} \quad$ : Kapasitas dasar (smp/jam)

$\mathrm{FCw}$ : Faktor penyesuaian lebar jalur lalin

FCsp : Faktor penyesuaian pemisah arah

FCsf : Faktor penyesuaian hambatan

FCcs : Faktor penyesuaian ukuran kota

\subsubsection{Tingkat Pelayanan (Level of Service)}

Tingkat pelayanan adalah suatu metode untuk memberikan batasan-batasan ukuran untuk dapat menjawab pertanyaan apakah kondisi suatu ruas jalan yang ada saat ini masih memenuhi 
syarat untuk di lalui oleh volume maksimum saat ini maupun peningkatan hingga yang akan datang. Tingkat pelayanan berdasarkan [15] dapat dinyatakan dalam rumus :

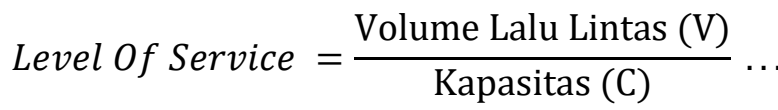

Tabel 2. Karakteristik tingkat pelayanan jalan

\begin{tabular}{|c|c|l|}
\hline $\begin{array}{c}\text { Batas Lingkup } \\
\text { V/C }\end{array}$ & $\begin{array}{c}\text { Tingkat } \\
\text { pelayana } \\
\mathrm{n}\end{array}$ & \multicolumn{1}{|c|}{ Ciri arus lalu lintas } \\
\hline $0,0 \mathrm{~s} / \mathrm{d} 0,19$ & $\mathrm{~A}$ & Lalu lintas bebas \\
\hline $0,20 \mathrm{~s} / \mathrm{d} 0,44$ & $\mathrm{~B}$ & Stabil \\
\hline $0,45 \mathrm{~s} / \mathrm{d} 0,69$ & $\mathrm{C}$ & Masih batas stabil \\
\hline $0,70 \mathrm{~s} / \mathrm{d} 0,84$ & $\mathrm{D}$ & Mendekati tidak stabil \\
\hline $0,85 \mathrm{~s} / \mathrm{d} 1,0$ & $\mathrm{E}$ & Arus tidak stabil \\
\hline$>1,0$ & $\mathrm{~F}$ & Dipaksakan / buruk \\
\hline
\end{tabular}

Sumber : MKJI, 1997

\subsubsection{Kecapatan Arus Bebas}

Kecepatan arus bebas (FV) didefinisikan sebagai kecepatan pada tingkat arus nol, yaitu keepatan yang akan dipilih pengemudi jika mengendarai kendaraan bermotor tanpa dipengaruhi oleh kendaraan bermotor lain di jalan.

\subsubsection{Kecepatan}

Menurut [17], kecepatan adalah laju perjalanan yang biasanya dinyatakan dalam kilometer perjam $(\mathrm{km} / \mathrm{jam})$, dan umumnya terbagi menjadi tiga jenis : a. Kecepatan setempat ; b.Kecepatan bergerah; c. Kecepatan Perjalanan.

\subsubsection{Tundaan}

Menurut [18], tundaan didefinisikan sebagai waktu tempuh tambahan untuk melewati simpang di bandingkan situasi tanpa simpang.

\subsection{Parkir}

Parkir adalah kendaraan yang tidak bergerak yang bersifat sementara.Fasilitas parkir adalah lokasi yang ditentukan sebagai tempat pemberhentian kendaraan yang bersifat sementara untuk melakukan kegiatan pada suatu kurun waktu.[19]

\subsubsection{Parkir menurut tipe}

Tipe parkir dapat dikelompokan sebagai berikut : Parkir menurut tempat, Parkir menurut posisi, Parkir menurut status parker, Parkir menurut jenis tujuan parker, Parkir menurut jenis kepemilikan dan pengoperasiannya.

\subsubsection{Satandart kebutuhan ruang parkir}


Menurut [20], Standart kebutuhan luas area kegiatan parkir berbeda antara yang satu dengan yang lain, tergantung pada beberapa hal. Standart ukuran kebutuhan ruang parkir dapat dilihat pada tabel 3 berikut :

Tabel 3. Ukuran kebutuhan parkir

\begin{tabular}{|c|c|c|}
\hline Peruntukan & $\begin{array}{l}\text { SPR untuk mobil } \\
\text { penumpang }\end{array}$ & $\begin{array}{c}\text { Kebutuhan } \\
\text { parkir }\end{array}$ \\
\hline $\begin{array}{l}\text { Pusat Perdagangan } \\
\text { a. Pertokoan } \\
\text { b. Pasar Swalayan } \\
\text { c. Pasar }\end{array}$ & $\begin{array}{l}\text { SRP } / 100 \mathrm{~m}^{2} \mathrm{~L} \text {. lantai efektif } \\
\text { SRP/100m } \mathrm{m}^{2} \mathrm{~L} \text {. lantai efektif } \\
\text { SRP/100m } \mathrm{m}^{2} \mathrm{~L} \text {. lantai efektif }\end{array}$ & $\begin{array}{l}3.5-7.5 \\
3.5-7.5 \\
3.5-7.5\end{array}$ \\
\hline $\begin{array}{l}\text { Pusat Perkantoran } \\
\text { a. Pelayanan bukan umum } \\
\text { b. Pelayanan umum }\end{array}$ & $\begin{array}{l}\text { SRP } / 100 \mathrm{~m}^{2} \mathrm{~L} . \text { lantai efektif } \\
\mathrm{SRP} / 100 \mathrm{~m}^{2} \mathrm{~L} \text {. lantai efektif }\end{array}$ & $\begin{array}{l}1.5-3.5 \\
1.5-3.5\end{array}$ \\
\hline $\begin{array}{l}\text { Sekolah } \\
\text { Hotel } \\
\text { Rumah Sakit } \\
\text { Bioskop }\end{array}$ & $\begin{array}{l}\text { SRP/Mahasiswa } \\
\text { SRP/Kamar } \\
\text { SRP/Tempat Tidur } \\
\text { SRP/Tempat duduk }\end{array}$ & $\begin{array}{l}0.7-1.0 \\
0.2-1.0 \\
0.2-1.3 \\
0.1-0.4\end{array}$ \\
\hline
\end{tabular}

Sumber : Pedoman perencanaan dan pengoperasian Fasilitas Parkir 1996.

\subsection{Analisa Penanganan}

Menurut [8], Kinerja jaringan akan terpengaruh oleh perubahan permintaan di daerah kajian. Dalam konteks kawasan pengembang hamper dapat dipastikan bahwa sisi permintaan akan meningkat sesuai dengan intensitas lahan apa adanya. Penanganan masalah mengacu pada kriteria evaluasi Derajat Kejenuhan (DS) setiap ruas jalan.

Jenis penanganan di ruas jalan dapat dikelompokan menjadi berikut :

1. Manajemen Lalu lintas (R1)

Pada prinsipnya penanganan ini ditekankan pada pemanfaatan ruas jalan.Jenis penanganan ini apabila DS berada antara $0.60 \mathrm{~s} / \mathrm{d} 0.80$.

2. Peningkatan ruas jalan (R2)

Penanganan ini mencakup perubahan fisik ruas jalan yang berupa pelebaran atau penambahan lajur sehingga kapasitas jalan dapat meningkat.Jenis penanganan ini dilakukan apabila nilai DS sudah lebih besar dari 0.80 .

3. Pembangunan jalan baru (R3)

Penanganan ini alternative terakhir dari pilihan R1 dan R2 di atas.Jenis penanganan ini dilakukan apabila pelebaran jalan atau penambahan lajur sudah tidak memungkinkan, 
terutama karena keterbatasan lahan serta kondisi lalu lintas yang nilai DS-nya lebih besar dari 0.80 .

\subsection{Pengumpulan Data dan Pengolahan Data}

\subsubsection{Data Sekunder}

Adalah data yang diperoleh dari lembaga atau instansi yang terkait dengan penelitian. Data tersebut dipergunakan untuk menentukan wilayah kajian atau daerah dampak.

\subsubsection{Data Primer}

Adalah data-data yang langsung di cari dan dikumpulkan oleh peneliti ke objek pengamatanya. Data primer yang digunakan dalam penelitian ini adalah volume arus lalu lintas, geometrik jalan, analisis dampak lalu lintas.

\subsubsection{Pelaksanaan Survai}

1. Pekerjaan Persiapan ; 2. Survai Pendahuuan; 3. Waktu pelaksanaan; 4. Metoda Survey.

\subsection{Pengembangan Model}

Dalam melakukan analisis transportasi digunakan beberapa model perhitungan tergantung pada ketersediaan data yang akan di pergunakan dalam perangkat lunak.

\subsection{Analisis Kinerja Ruas Jalan dan Persimpangan}

Analisis kinerja jaringan jalan yang di lakukan oleh penulis disini terdiri atas analisis kinerja ruas jalan dan kinerja simpang untuk daerah eksternal dan analisis antrian pada jalan akses yang dilakukan baik tanpa pembangunan maupun dengan pembangunan.

\subsection{Analisis Penanganan Dampak}

Tahapan analisis penanganan dampak ialah tahapan di mana skema yang diusulkan dikaji ke-efektif-annya dengan parameter mikro rekayasa lalu lintas. Analisis yang dilakukan terdiri dari analisis jaringan jalan.

\subsection{Rekomendasi}

Agar kondisi kinerja lalu lintas tidak mengalami penurunan kinerja yang signifikan akibat Revitalisasi Pasar Sumbergempol Tulungagung maka dapat dilakukan penanganan antara lain dengan Rekayasa Lalu Lintas dan Manajemen Lalu Lintas.

\section{HASIL DAN PEMBAHASAN}

\subsection{Analisa Kondisi Saat ini 3.1.1 Lokasi Studi}


Lokasi kegiatan Penelitian ini terletak pada sebelah barat stasiun sumbergempol tepatnya pada ruas jalan Nasional Tulungagung-Blitar. Peruntukan lahan disekitar lokasi merupakan kawasan Pendidikan, Perkantoran, dan Pertokoan.

Tabel. 4 Identifikasi Segmen

\begin{tabular}{|c|c|c|}
\hline No & Uraian & Keterangan \\
\hline 1 & Kota & Kabupaten Tulungagung \\
\hline 2 & Ukuran Kota & Kecil \\
\hline 3 & Tipe Daerah & 100 Meter \\
\hline 4 & Panjang Segmen & Kolektor Sekunder \\
\hline 5 & Kelas Jalan & Jam Puncak \\
\hline 6 & Periode Waktu Analisa & \\
\hline
\end{tabular}

Sumber : Hasil Analisa

\subsubsection{Analisa Transportasi}

\section{Jaringan Jalan}

Jaringan Jalan yang berada di kawasan penelitian adalah kolektor sekunder merupakan ruas jalan pada kawasan perkotaan Tulungagung.

2. Perlengkapan Jalan

Pengaturan lalu lintas di ruas jalan harus dilengkapi dengan marka jalan, rambu lalu lintas, alat pemberi isyarat lalu lintas serta juga kalau di perlukan jembatan penyeberangan.

\subsubsection{Beban Lalu Lintas Wilayah Studi Kondisi saat ini.}

1. Sarana dan Prasarana

Pemakai jalan pada prinsipnya selalu mengharapkan kondisi jalan yang cepat, aman, nyaman, ekonomis. Bangkitan maupun tarikan dari pasar ini tentunya mempengaruhi kondisi lalu lintas disekitarnya.

\section{Areal Parkir}

Untuk penyediaan areal parkir pasar tersebut harus menyediakan ruang parkir yang cukup bagi pengunjung. Dengan adanya ruang parkir yang memadai akan menata kondisi lalu lintas sekitar agar tertib dan teratur.

Tabel 5. Pertumbuhan Kendaraan th. 2004-2017

\begin{tabular}{|c|c|c|c|c|c|c|}
\hline \multirow{2}{*}{ No } & \multirow{2}{*}{$\begin{array}{c}\text { JENIS } \\
\text { KENDARAAN }\end{array}$} & \multicolumn{4}{|c|}{ JUMLAH } & \multirow[t]{2}{*}{ Ket } \\
\hline & & 2014 & 2015 & 2016 & 2017 & \\
\hline 1 & Sepeda Motor & 416.591 & 432.265 & 455.833 & 468.057 & \\
\hline 2 & Jeep & 3.035 & 3.032 & 3.285 & 3.492 & \\
\hline 3 & Sedan & 3.779 & 3.564 & 3.818 & 4.023 & \\
\hline 4 & Colt Station & 10.355 & 10.052 & 10.273 & 10.212 & \\
\hline 5 & Truck & 5.096 & 5.300 & 5.592 & 5.382 & \\
\hline 6 & Pickup & 9.060 & 9.438 & 10.532 & 11.342 & \\
\hline
\end{tabular}




\begin{tabular}{|c|c|c|c|c|c|c|}
\hline \multirow{2}{*}{ No } & \multirow{2}{*}{$\begin{array}{c}\text { JENIS } \\
\text { KENDARAAN }\end{array}$} & \multicolumn{4}{|c|}{ JUMLAH } & \multirow[t]{2}{*}{ Ket } \\
\hline & & 2014 & 2015 & 2016 & 2017 & \\
\hline 7 & $\overline{\text { Bus }}$ & 560 & $\overline{585}$ & $\overline{585}$ & $\overline{563}$ & \\
\hline & JUMLAH & 448.476 & 464.236 & 489.918 & 503.071 & \\
\hline & PERTUMBUHAN & & $3,5 \%$ & $5,5 \%$ & $2,7 \%$ & \\
\hline
\end{tabular}

Sumber : Kab. Tulungagung dalam angka 2018.

Dari tabel diatas dapat dilihat bahwa pertumbuhan pada tahun 2016 - 2017 sebesar 2,7\%.

\subsubsection{Kinerja Lalu Lintas Wilayah Studi Saat ini}

1. Kondisi Lalu Lintas

Jalan Raya Sumbergempol merupakan salah satu ruas jalan antar kota yang mempunyai lebar efektif \pm 7 meter, dengan lebar bahu jalan \pm 1.5 meter kanan kiri.

Dari hasil perhitungan analisis yang mengacu pada MKJI 1997 dapat di lihat di bawah ini :

a. Kapasitas Ruas Jalan

Tabel 6. Kapasitas Ruas Jalan

\begin{tabular}{|c|c|c|c|c|c|c|c|}
\hline NO & NAMA RUAS & $\mathrm{C}_{\mathrm{O}}$ & $\mathrm{FC}_{\mathbf{W}}$ & $\mathrm{FC}_{\mathbf{S P}}$ & $\mathbf{F C}_{\mathbf{S F}}$ & $\mathbf{F C}_{\mathbf{C S}}$ & $\mathrm{C}$ \\
\hline 1 & Jl. Raya Sumbergempol & 2900 & 1 & 0.97 & 0.9 & 1.04 & 2632.96 \\
\hline
\end{tabular}

Sumber : Hasil Analisa.

Tabel 7. Inventarisasi Ruas Jalan

\begin{tabular}{|c|c|c|c|c|c|}
\hline \multirow{2}{*}{ No } & NAMA RUAS & \multirow{2}{*}{$\begin{array}{c}\text { Lebar efektif } \\
(\mathbf{m})\end{array}$} & $\begin{array}{c}\text { N } \\
\text { (lajur) }\end{array}$ & $\begin{array}{c}\text { tipe } \\
\text { jalan }\end{array}$ & $\mathbf{C}$ \\
\cline { 5 - 6 } & & 7 & 2 & $2 / 2$ UD & 2632.96 \\
\hline $\mathbf{1}$ & Jl. Raya Sumbergempol & 7 & 2 & \\
\hline
\end{tabular}

Sumber : Hasil Analisa

b. Volume Lalu lintas

Tabel 8. Volume LHR

\begin{tabular}{|c|c|r|r|c|}
\hline No & Nama Jalan & $\begin{array}{r}\text { Volume per } \\
\text { arah }\end{array}$ & Volume & Ket \\
\hline 1 & J1. Raya Sumbergempol & $\begin{array}{r}718,8 \\
697,8\end{array}$ & 1416,6 & \\
\hline
\end{tabular}

Sumber : Hasil Analisa

c. V/C Ratio

Tabel 9. V/C Ratio Ruas Jalan \& LOS Kondisi Existing

\begin{tabular}{|c|c|c|c|c|}
\hline No & NAMA JALAN & VOLUME & KAPASITAS & VC RATIO \\
\hline $\mathbf{1}$ & J1. Raya Sumbergempol & 1416,6 & 2632,9 & 0,53 \\
\hline
\end{tabular}

Sumber : Hasil Analisa 
Dari tabel diatas terlihat bahwa secara umum ruas jalan yang ada disekitar pasar kinerjanya kurang bagus. Karena mempunyai tingkat pelayanan dengan nilai $\mathrm{C}$ yang artinya kinerja jalan masih dalam batas stabil.

\subsection{Analisa Kondisi yang Akan Datang}

\subsubsection{Prediksi Kondisi Lalu Lintas Setelah Pembangunan (Existing).}

Unjuk kinerja masa operasional perlu dikaji untuk mengetahui seberapa besar kegiatan operasional pasar berpengaruh terhadap kinerja jaringan jalan. Pada masa operasional, beberapa parameter yang digunakan adalah sebagai berikut :

\section{Tarikan Perjalanan}

Untuk mengetahui besarnya jumlah tarikan perjalanan total dari pasar, maka metode yang digunakan adalah menggunakan metode objek pembanding pasar yang sejenis,yaitu pasar Panjerejo yang terletak din desa Panjerejo, Kec. Rejotangan, Kab. Tulungagung. Berikut adalah tabel perhitungannya :

Tabel 10. Perhitungan tarikan perjalanan

\begin{tabular}{|c|l|c|c|c|l|}
\hline \multirow{2}{*}{ No } & \multicolumn{1}{|c|}{ Uraian } & Luas & \multicolumn{2}{c|}{ Jumlah Perjalanan } & \multirow{2}{*}{ Sat. } \\
\cline { 4 - 5 } & & & Tarikan & Bangkitan & \\
\hline 1 & Luas lantai bangunan pembanding & 2,838 & & & $\mathrm{~m} 2$ \\
\hline 2 & Jumlah perjalanan pembanding & & 755 & 463 & smp/hari \\
\hline 3 & Total perjalanan jam sibuk kegiatan & & 91.7 & 62.5 & smp/jam \\
\hline 4 & Persentase jam sibuk kegiatan & & $12 \%$ & $13 \%$ & \\
\hline 5 & Trip rate pasar pembanding & & 26.60 & 16.31 & $1100 \mathrm{~m} 2$ \\
\hline 6 & Luas lantai bangunan Pasar & 2,750 & & & $\mathrm{~m} 2$ \\
\hline 7 & Jumbergempol & & & & \\
\hline 8 & Total Perjalanan Sibuk Kegiatan & & 88.9 & 60.6 & smp/jam \\
\hline
\end{tabular}

Sumber : Hasil Analisa.

Dari hasil survei terhadap objek pembanding. Jumlah tarikan perjalanan pada pasar Sumbergempol diprediksikan adalah sebesar 88,9 smp/jam sedangkan bangkitannya adalah sebesar 60,6 smp/jam.

2. Pemilihan Moda

Pemilihan moda dilakukan berdasarkan persentase masing-masing moda tarikan perjalanan pada objek pembanding. Berdasarkan hasil survei dari objek pembanding, persentase penggunaan sepeda motor adalah $68,55 \%$, sedangkan persentase penggunaan mobil adalah $16.00 \%$.

3. Pembebanan Kinerja Ruas Jalan dengan Pembangunan.

Dengan Prediksi jumlah tarikannya sebesar 88,9 smp/jam, berikut adalah perkiraan kinerja ruas jalan tersebut : 
Tabel 11. Kinerja Ruas Jalan Masa Operasional tahun 2019

\begin{tabular}{|c|l|c|c|c|c|}
\hline No & NAMA JALAN & VOLUME & KAPASITAS & $\begin{array}{c}\text { VC } \\
\text { RATIO }\end{array}$ & LOS \\
\hline $\mathbf{1}$ & Jl. Raya Sumbergempol & 1505,5 & 2632,9 & 0,57 & C \\
\hline
\end{tabular}

Sumber : Hasil Analisa

Berdasarkan hasil analisa, secara umum tingkat pelayanan jalan di wilayah studi tetap berada pada level C yang artinya kinerja jalan masih dalam batas stabil.

\subsubsection{Analisa Kinerja Jaringan Jalan Tahun Rencana dengan Pembangunan (2024)}

Perhitungan kinerja ruas jalan pada tahun rencana (2024) dengan pembangunan adalah :

Tabel 12. Kinerja Ruas Jalan Masa Operasional Tahun 2024

\begin{tabular}{|c|l|c|c|c|c|}
\hline No & NAMA JALAN & VOLUME & KAPASITAS & $\begin{array}{c}\text { VC } \\
\text { RATIO }\end{array}$ & LOS \\
\hline $\mathbf{1}$ & Jl. Raya Sumbergempol & 1618.5 & 2632,9 & 0,61 & $\mathrm{C}$ \\
\hline
\end{tabular}

Sumber : Hasil Analisa.

Dengan adanya pertumbuhan lalu lintas sebesar $2,7 \%$, maka terjadi penurunan tingkat pelayanan ruas jalan menjadi $0,61 \mathrm{smp} / \mathrm{jam}$ akan tetapi masih berada pada level $\mathrm{C}$ masih dalam batas stabil.

\subsubsection{Analisa Kebutuhan Parkir}

Pihak pengembang Pasar harus menyediakan luasan areal parkir yang disesuaikan dengan kebutuhan. Sehingga nantinya pengunjung tidak akan kesulitan untuk memarkirkan kendaraannya.

Dari Tabel 3. Pengembang harus menyediakan areal parkir minimal untuk sepeda motor sebesar 144,3 m2. Sedangkan untuk mobil areal parkir minimal sebesar 1203,13 m².

\section{KESIMPULAN}

Dari Hasil analisa tersebut dapat ditarik kesimpulan bahwa :

1. Revitalisasi Pasar Rakyat Sumbergempol diperkirakan akan menarik perjalanan baru sebesar $88,9 \mathrm{smp} / \mathrm{jam}$ dan membangkitkan perjalanan baru sebesar 60,6 smp/jam.

2. Hasil Penilitian Kinerja Lalu Lintas di wilayah sekitar pada tahun penelitian dan tahun rencana (2024) adalah sebagai berikut :

a. Kondisi ruas jalan di sekitar pasar sebelum di lakukan revitalisasi mempunyai V/C Ratio 0,53 dan memiliki kinerja lalu lintas pada level $\mathrm{C}$ yang masih dalam batas stabil.

b. Prediksi arus lalu lintas di sekitar lokasi penelitian pada tahun 2019 setelah beroperasi memiliki VC Ratio 0,57 dan kinerja lalu lintas masih pada level $\mathrm{C}$ yang masih dalam batas stabil. 
c. Prediksi arus lalu lintas di sekitar lokasi Penelitian pada tahun 2024 mendatang diprediksikan memiliki VC Ratio 0,61. Penurunan LOS tapi masih stabil dan perlu kajian di tahun berikutnya.

3. Dampak yang akan terjadi karena (Level Of Service / LOS) pada ruas jalan tersebut berada pada level C, yang penentuannya berdasarkan [7] adalah sebagai berikut :

- Arus stabil tetapi pergerakan kendaraan dikendalikan oleh volume lalu lintas yang lebih tinggi dengan kecepatan sekurang kurangnya 60 km/jam;

- Kepadatan lalu lintas sedang karena hambatan internal lalu lintas meningkat;

- Pengemudi memiliki keterbatasan untuk memilih kecepatan, pindah jalur atau mendahului.

4. Pihak pengembang Pasar dimaksud harus menyediakan luasan areal parkir untuk sepeda motor sebesar 144,3 m2. Sedangkan untuk areal parkir mobil minimal sebesar 1203,13 m2.

\section{SARAN}

Beberapa saran yang dapat dilaksanakan untuk mengantisipasi terjadinya permasalahan lalu lintas di sekitar lokasi pembangunan adalah sebagai berikut : Melakukan penataan desain geometrik radius belok kendaraan di pintu masuk / pintu keluar, pemasangan lampu peringatan warna kuning ( Warning Light ), tidak membangun pagar yang tinggi di dekat pintu masuk maupun pintu keluar kantor, melakukan penataan sirkulasi lalu lintas di dalam kawasan pasar, pemasangan rambu larangan parkir, pemasangan rambu petunjuk arah masuk kendaraan, pemasangan rambu petunjuk parkir, pemasangan rambu petunjuk lokasi pasar, penataan tempat parkir.

\section{UCAPAN TERIMAKASIH}

Dalam penyusunan artikel ini, penulis ucapkan terimakasih kepada dosen pembimbing dan Universitas Kadiri. Penulis berharap agar artikel ini dapat bermanfaat bagi pembaca.

\section{DAFTAR PUSTAKA}

[1] A. D. Limantara, A. I. Candra, and S. W. Mudjanarko, "Manajemen Data Lalu Lintas Kendaraan Berbasis Sistem Internet Cerdas Ujicoba Implementasi Di Laboratorium Universitas Kadiri," 2017.

[2] S. J. Legowo and D. Anggoro, "Studi Evaluasi Dampak Lalu Lintas Akibat Pembangunan Stasiun Pengisian Bahan Bakar Umum ( Spbu ) Manahan,” pp. 601-609, 2014.

[3] A. I. Candra et al., "PENGECEKAN KELAYAKAN BANGUNAN GEDUNG SMA NEGERI 1 KOTA KEDIRI YANG DIGUNAKAN UNTUK AKTIFITAS BELAJAR BELAJAR,” Ukarst J. Univ. Kadiri Ris. Tek. Sipil, vol. 2, no. 2, pp. 108-116, 2019. 
[4] E. H. Suntoyo, A. Ridwan, and S. Winarto, "Manajemen Rekayasa Lalu Lintas Pengembangan Wisata Kampung Coklat," J. Adm. Publik, 2019.

[5] F. A. Lestari and Y. Apriyani, "ANALISIS DAMPAK LALU LINTAS AKIBAT ADANYA PUSAT PERBELANJAAN DIKAWASAN PASAR PAGI PANGKALPINANG TERHADAP KINERJA RUAS JALAN," J. Fropil, vol. 2, no. 1, pp. 32-44, 2014.

[6] E. H. Sunyoto, A. Ridwan, and S. Winarto, "MANAJEMEN REKAYASA LALU LINTAS PENGEMBANGAN WISATA KAMPUNG COKLAT," Jurmateks, vol. 2, no. 1, pp. 29-38, 2019.

[7] Anonim, "Peraturan Menteri 75 tahun 2015 tentang Penyelenggara Andalalin." Menteri Perhubungan Republik Indonesia, Jakarta, 2015.

[8] O. Z. Tamin, Perencanaan dan Pemodelan Transportasi, Edisi Kedua. 2000.

[9] R. Rahman, “Analisa Dampak Lalu Lintas (Studi Kasus: Studi Kemacetan di Jalan Ngagel Madya Surabaya)," SMARTek, vol. 8, no. 4, pp. 317-332, 2010.

[10] A. Y. Nurkafi, S. Winarto, and A. I. Candra, "ANALISA KINERJA SIMPANG TAK BERSINYAL JALAN SIMPANG BRANGGAHAN NGADILUWIH KABUPATEN KEDIRI," Jurmateks, vol. 2, no. 1, pp. 164-178, 2019.

[11] O. Z. Tamin, Perencanaan dan Pemodelan Transportasi. ITB Bandung, 1997.

[12] R. J. Salter, Highway Traffic Analysis and Design, Second Edi. London, 1989.

[13] B. A. Harsono, S. Winarto, and Y. C. S, "PERENCANAAN PENINGKATAN JALAN PADA RUAS JALAN PACITAN-NGADIROJO,”Jurmateks, vol. 1, no. 2, pp. 291-302, 2018.

[14] S. Sukirman, Dasar-Dasar Perencanaan Geometrik Jalan. Bandung: Nova, 1994.

[15] Anonim, Manual Kapasitas Jalan Indonesia. Jakarta, 1997.

[16] Anonim, Pedoman Kapasitas Jalan Indonesia. 2014.

[17] F. D. Hobbs, Perencanaan dan Teknik lalu Lintas. Jogjakarta: Fakultas Teknik Universitas Gajah Mada, 1995.

[18] A. Munawar, Manajemen Lalu Lintas Perkotaan. Jogjakarta: Beta Offset, 2004.

[19] I. Abubakar et al., "Pedoman Perencanaan dan Pengoperasian Fasilitas Parkir." Direktorat Jenderal Perhubungan Darat, Jakarta, 1998.

[20] Anonim, Pedoman Teknis Penyelenggaraan Fasilitas Parkir. 1996. 